\title{
O negro no contexto das novas estratégias do capital: desemprego, precarização e informalidade
}

\section{Black people in the context of the new strategies of the capital: unemployment, precariousness and informality}

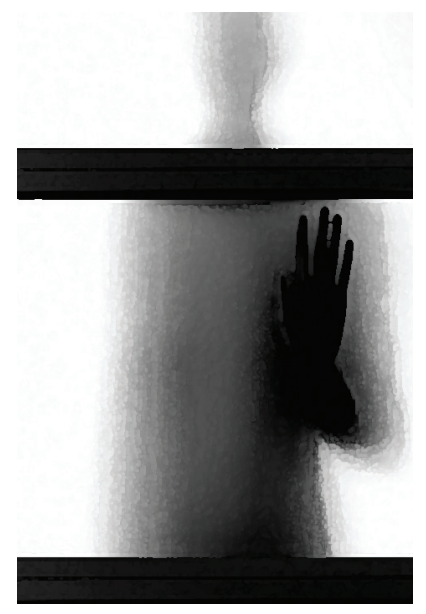

Tereza Cristina Santos Martins*

Resumo: O presente artigo parte do entendimento de que apesar da crise e das transformações operadas no mundo do trabalho atingirem de modo geral a "classe-que-vive-do-trabalho", ${ }^{1}$ as novas estratégias de produção e subordinação do trabalho ao capital não afetam igualmente brancos e negros. Nesse sentido, o seu objetivo é debater a condição de desigualdade do negro no contexto das novas estratégias de produção e subordinação do trabalho ao capital. Trata-se de identificar, por meio dos indicadores das desigualdades raciais, a desigualdade do trabalhador negro no mercado de trabalho brasileiro.

Palavras-chave: Desigualdade racial. Desemprego. Trabalho precário e informal.

\begin{abstract}
This paper Takes the view that despite the crisis and the transformations wrought in the work world in general reach the "class-who-livres-of-work", the new production strategies and subordination of labor to capital is not equally affect and blacks. In this sense, the goal is to discuss the condition of inequality in the black in the context of new production strategies an subordination of labor to capital. It is identified by the indicators of racial inequality, the inequality of black work.
\end{abstract}

Keywords: Racial inequality. Unemployment. Precarious employment, informal employment, the labor market.

* Doutora em Serviço Social pela Universidade Federal de Pernambuco/Recife, Brasil; membro do Grupo de Pesquisa Trabalho, Questão Social e Gênero da UFS. E-mail: trzamartins@gmail.com.

1. Antunes (1997). 


\section{Apresentação}

M

esmo considerando o caráter estrutural da crise capitalista e, consequentemente, os problemas estruturais por ela gestados, e, ainda, tendo presente que o desemprego nesse contexto - como um dos mais importantes problemas contemporâneos - independe de requisitos como qualificação e escolarização da força de trabalho, ainda assim observa-se que o desemprego, as ocupações precárias e informais têm afetado mais os trabalhadores negros do que os brancos. Desta forma, dar conta do debate, o presente artigo está dividido em três seções. A primeira analisa, em traços largos, a crise do capitalismo e as mudanças ocorridas na sociedade do trabalho. Na segunda seção busca-se, a partir de elementos históricos da formação social do Brasil, compreender a discriminação racial como uma marca impressa na constituição do capitalismo brasileiro, compreendendo, ainda, a discriminação racial associada às determinações econômicas da lógica capitalista. Nesse sentido, busca-se levantar, na gênese do capitalismo brasileiro, os elementos que ajudam a pensar o desemprego, bem como as inserções da força de trabalho negra nas ocupações precárias e informais. Finalmente, a terceira seção traz a análise percentual de desemprego da população negra (preta e parda) em relação à população branca, bem como as suas inserções nas ocupações precárias e informais desencadeadas pelas antigas e novas estratégias de produção e valorização do capital.

\section{Crise e mudança na sociedade do trabalho}

A crise do sistema capitalista e as mudanças no mundo do trabalho nunca, na história do desenvolvimento capitalista, afetaram tão profundamente a sociedade e a "classe-que-vive-do-trabalho" (Antunes, 1997) quanto no período recente. A rigor, as transformações no mundo do trabalho estão relacionadas à crise instaurada no capitalismo mundial. A fase expansionista do capitalismo maduro (Mandel, 1982) começa a dar sinais de esgotamento em fins dos anos 1960. Na verdade, do ponto de vista econômico, a situação excepcional envolvendo a economia de guerra e a ascensão do fascismo esteve na base dessa terceira onda de expansão da história do capital (os anos de ouro). Por outro lado, os fatores políticos vinculados ao contexto da Guerra Fria e o recente Estado socialista possibilitaram a valorização do Welfare State. Contudo, o capitalismo "maduro" cumprindo uma tendência inerente a sua lógica, inicia uma de suas crises nos anos 1970. 
É preciso observar, no entanto, que já nos fins da década de 1960 a busca contínua de extração da mais-valia conduziu a um deslocamento do trabalho vivo pelo trabalho morto. A automação intensificou ainda mais as contradições, a exemplo da "socialização crescente do trabalho agregado à redução do emprego e à apropriação privada; da produção de valores de uso e a realização de valores de troca; o processo de trabalho e o de valorização" (Mandel, 1982, p. 138-139). Diante da incapacidade do sistema de manter a reprodução da mais-valia e de conter as contradições que lhes são inerentes, tornou urgente instaurar um processo heurístico de reconversão da ordem do capital em nível internacional, ou seja, instaurar a acumulação flexível (Harvey, 1996).

O que se colocou na base da crise clássica de superprodução dos anos de 1970 foi o desemprego, provocado pela adoção de técnica de produção intensiva e economizadora de mão de obra; a isso se somam a alta dos preços de matéria-prima, a queda do volume do comércio mundial e um poder de organização da classe trabalhadora. Todos esses elementos contribuíram para a queda da taxa média de lucro. Além disso, a inflação provocou a busca de valores-refúgio pela via da especulação financeira. Por sua vez, a expansão do crédito em meio a um processo inflacionário resultou na aceleração dos processos de endividamento, tanto dos setores privados quanto dos públicos (Mandel, 1990, p. 39).

Para fazer frente à crise que se instaura, nos anos 1980, a reação burguesa à corrida tecnológica em busca do diferencial de produtividade do trabalho, como fonte de superlucros (Mandel, 1982), acaba gerando o desemprego. Desemprego que, diferentemente do fenômeno vivenciado nas fases anteriores do desenvolvimento capitalista, de acordo com Mészáros (2006), diz respeito a um problema de ordem estrutural e mesmo nos países chamados de "capitalismo avançado", a exemplo do Japão, a deterioração das condições de trabalho não permite que nem a falsa ideia de "flexibilidade" como saída redentora oculte as sérias implicações decorrentes da expansão e da acumulação do capital. É diante da essência desse fenômeno que o autor atribui o significado de trabalho temporário como precarização, embora se pretenda empregar-lhe o termo "emprego flexível".

Portanto, estamos diante de um fenômeno que surgiu como característica essencialmente necessária e já deteriorada dessa crise estrutural, cujos desdobramentos sob as condições de desemprego se apresenta em um

problema que não se restringe [...] [aos] trabalhadores não qualificados, mas atinge também ...[os] altamente qualificados. [...] Da mesma forma, a tendência da amputação "racionalizadora" não está mais limitada aos "ramos periférico de uma indústria obso- 
leta", mas [os] mais desenvolvidos e modernizados setores da produção. Portanto, não estamos mais diante dos subprodutos "normais" e voluntariamente aceitos do "crescimento e do desenvolvimento", mas de um movimento em direção a um colapso; nem tampouco diante de problemas periféricos dos "bolsões de subdesenvolvimento", mas diante de uma contradição fundamental do modo de produção capitalista como um todo, que transforma até mesmo as últimas conquistas do "desenvolvimento", da "racionalização" e da "modernização" em fardos paralizantes de subdesenvolvimento crônico. E o mais importante de tudo é que quem sofre todas as consequências dessa situação não é mais a multidão socialmente impotente, apática e fragmentada das pessoas "desprivilegiadas", mas todas as categorias de trabalhadores qualificados e não qualificados: ou seja, [...] a totalidade da força de trabalho da sociedade. (Mészáros, 2009, p. 1005)

Nesse sentido, o desemprego estrutural se coloca como característica dominante dessa fase do desenvolvimento histórico do capitalismo. Essa afirmação se sustenta no fato de que existem mais de 40 milhões de desempregados nos países industrialmente mais desenvolvidos. A Europa possui um contingente com mais de 20 milhões, a Alemanha ultrapassou a marca dos 5 milhões. A Índia encontra-se com não menos do que 336 milhões de pessoas desempregadas. A intervenção do FMI aprofunda ainda mais as condições dos desempregados. Nos antigos países pós-capitalistas, da Rússia à Hungria o desemprego é maciço. Na Hungria existem cerca de 500 mil desempregados. Na Federação Russa a situação é igualmente ruim. O Vietnã e mesmo a China não se colocam como exceções. Embora com uma economia seja especial e politicamente controlada, estima-se que existam 268 milhões de desempregados (Mészáros, 2006).

Não por acaso, a configuração dessa fase de desenvolvimento faz com que o sistema capitalista se constitua de uma rede fechada de inter-relações e de interdeterminações por meio da qual não é possível vislumbrar saídas paliativas e parciais ao desemprego. Ao contrário, a "globalização", como uma falsa ideia de expansão e da integração do capital, como um fenômeno supostamente novo e destinado a responder a todos os problemas, não passa de um "modo antagônico pelo qual o avanço produtivo e o controle do metabolismo social lançam parcela crescente da humanidade na categoria de trabalho supérfluo" (Idem, p. 31)

Nessa direção, o desenvolvimento do mais dinâmico sistema produtivo da história acaba por criar um número cada vez maior de pessoas supérfluas, sem com isso torná-las supérfluas como consumidores. O que há de novo no fenômeno atual de desemprego do sistema globalmente integrado, segundo Mészáros (2006), "é que as contradições ocorridas em qualquer uma de suas partes específicas compli- 
cam e agravam os problemas de outras partes e, consequentemente, de sua totalidade" (p. 32). Assim, a mesma necessidade de diminuir custos significa a mesma necessidade de produzir desemprego e vice-versa. Essa se constitui em "imperativos antagônicos do capital, da busca de lucro e da acumulação, aos quais [o capital] não pode renunciar e, [muito menos] pode se restringir segundo princípios racional e humanamente gratificantes" (Idem).

O complexo processo sinalizado até agora não rebateu apenas no plano econômico e político. Repercutiu e serviu de base de sustentação, no plano ideocultural, o debate acerca do pretenso fim da história e do capitalismo. Nesse sentido, cabe, ao menos sinteticamente, lançar alguns elementos que contribuam na desmistificação dessa afirmação, enquanto detentora do caldo ideocultural pós-moderno.

Segundo Teixeira (1996), a ideia de que a humanidade teria atingido o topo do processo histórico, associada a uma consciência de que a modernidade teria envelhecido, levou teóricos a afirmar o desaparecimento das determinações que sustentam a forma capitalista, tanto de organização da produção quanto da distribuição da riqueza social produzida.

De fato, os princípios padronizados, especializados, sincronizados, centralizados e maximizados, que sustentaram e organizaram a produção e a distribuição da riqueza - influenciando as diversas dimensões da vida — sofreram profundas transformações (Teixeira, 1996). No entanto, Teixeira (1996) afirma que a ideia do fim do capitalismo parte da "consciência imediata da práxis utilitária para construir seus conceitos e juízos sobre a realidade". Na verdade, segundo o autor, é preciso avançar para além dessa consciência, retomando o resultado das análises, no sentido de investigar para perguntar se as transformações ocorridas no sistema produtivo significam o fim do capitalismo como "sistema articulador e definidor da produção, do consumo, da circulação (da troca) e da distribuição" (Idem, p. 28). Aqui se impõe a necessidade de compreender as formas de produção que emergiram na história do capitalismo, como exigência a valorização do capital.

É com a grande indústria que o capitalismo superou as barreiras que o impediam de dominar o trabalho. De fato, segundo Teixeira (1996), a partir da grande indústria, as máquinas passam a empregar o trabalhador. $\mathrm{O}$ trabalho virtuoso foi destruído e, assim, o trabalho abstrato ganhou realidade "tecnicamente tangível", ou seja, a nivelação geral das operações possibilitou deslocar os trabalhadores de uma máquina para outra, sem que com isso demandasse treinamento especial. Ademais, a produção de máquinas, equipamentos e instalações etc. possibilitou a substituição do trabalho vivo pelo trabalho morto, dando-lhe, consequentemente, condições para controlar o nível e o movimento dos salários. 
A despeito dessa superação, "não permite ao capital se afirmar como sujeito absoluto" (Idem, p. 68). Mesmo porque, para dominar, o capital desenvolve as forças produtivas, e uma vez realizado tal feito, "nega as bases de sua própria valorização: o trabalho vivo como criador de valor" (p. 68). Nesse sentido, as transformações operadas na sociedade do trabalho, ao contrário de uma indicação do fim do capitalismo, como quer Habermas e Giannoti, dizem respeito nada mais que à busca de novas formas de produção de mercadorias, sem as quais o sistema não tem como sair de sua crise estrutural.

É nesse contexto que o desemprego, enquanto necessidade impressa pela busca de "diminuição dos custos" e da acumulação, se coloca como necessidade do capital, ou seja, a rigor

Ou o capital mantém seu inexorável impulso em direção aos objetivos de autoexpansão, não importa quão devastadoras sejam as consequências, ou se torna incapaz de controlar o metabolismo social da reprodução. [...] as soluções parciais não serão capazes de prestar sequer a mais superficial atenção aos sofrimentos humanos, até porque é a primeira vez na história que a dinâmica [...] do controle social metabólico autoexpansivo [que o] sistema expele [...] uma maioria esmagadora de seres humanos do processo de trabalho. Este é o sentido profundamente perturbador da "globalização". (Mészáros, 2006, p. 32)

A breve reflexão acerca dos elementos que se colocam no debate da crise e das transformações desencadeadas a partir da necessidade de valorização do capital levanta algumas questões fundamentais para pensar os fenômenos advindos desse processo na realidade das sociedades. A primeira diz respeito à necessidade de compreendê-los a partir das particularidades e dos processos sócio-históricos das sociedades. No caso brasileiro, entendê-los a partir das particularidades presentes desde a formação social do país. O segundo diz respeito aos impactos relativamente desiguais desses fenômenos na sociedade como um todo e, particularmente, nas classes sócias e no interior destas. No caso em análise, como esses fenômenos atingem desigualmente a classe trabalhadora negra e branca.

Nesses termos, antes de avançarmos na análise acerca dos fenômenos que emergem com as novas estratégias de produção e subordinação do trabalho ao capital, convém realizar uma análise sobre o processo de formação social brasileiro, priorizando a constituição do capitalismo no país, sem a qual é impossível entender o porquê de, nessa fase de desenvolvimento do sistema capitalista, ser a força de trabalho negra a mais atingida pelos fenômenos: desemprego, trabalho precário e informal. 


\section{0 mercado de trabalho em formação: a construção do "lugar" do negro}

Com o fim do trabalho escravo e da proclamação da República, o monopólio do poder, o controle sobre o Estado e o domínio político passam a ser exercidos pelos grandes proprietários. Diante dos seus interesses econômicos e políticos, o índio, o negro e mesmo o branco nacional eram questões que a nascente burguesia remetia a último plano. Isso porque as pretensões de redefinição social e cultural do trabalho conduziam-se no sentido de uma política de valorização do imigrante, num processo em que o negro ao entrar nas novas condições e relação de produção vê-se profundamente bloqueado pela ideia de trabalho assalariado associado a uma força de trabalho estrangeira e branca. Nesse sentido,

o "estrangeiro" aparecia, aí, como a grande esperança nacional de progresso por saltos. Nos demais setores, imperavam as conveniências e as possibilidades, escolhidas segundo um senso de barganha que convertia qualquer decisão em "ato puramente econômico". Desse ângulo, onde o "imigrante" aparecesse, eliminava fatalmente o pretendente "negro" ou "mulato", pois entendia-se que ele era o agente natural do trabalho. (Fernandes, 1978, p. 27)

Numa conjuntura em que o processo de constituição capitalista se efetivava, o trabalho assalariado se coloca numa direção essencialmente deformada e excludente, de valorização do trabalhador branco (o imigrante europeu) como símbolo da redefinição social e cultural do trabalho no país. Daí porque a constituição do capitalismo no país, ao imprimir a exploração como condição fundamental da lógica capitalista, imprimiu nessa lógica a discriminação racial como insígnia do modo de produção baseado no trabalho livre. Sem dúvida, o que estava em jogo, segundo Ianni (1991), era "redefinir o trabalhador para redefinir a força de trabalho" (p. 25). Tanto assim que o arianismo que pautava o processo de revolução burguesa partia da tese da luxúria e da preguiça do negro, do índio e até mesmo do branco nacional. O que está posto nesse processo é a busca, por parte da burguesia emergente, das melhores e diferenciadas condições para a produção e a ampliação do lucro. Tanto que

o período subsequente de domínio republicano teve consequências catastróficas para a população negra, que, particularmente no estado de São Paulo, sofreu uma exclusão tripla das camadas dominantes da vida nacional. As práticas formais e informais da República negaram a participação política a praticamente toda população. O esforço para refazer o Brasil à imagem da Europa, e a doutrina do branqueamento, excluíam 
intencionalmente os afro-brasileiros desta nova sociedade republicana que estava se estabelecendo. E as políticas trabalhistas do governo do estado de São Paulo barraram a participação dos afro-brasileiros na economia que rapidamente se desenvolvia. (Andrews, 1998, p. 365-366)

Os efeitos desse processo de impressão da discriminação racial na lógica capitalista vão ser evidenciados no período anterior à industrialização e urbanização no país (décadas de 1940 e 1950), quando a abundância de força de trabalho se faz notar no contexto brasileiro. Esse exército de desocupados se vincula ao processo de transição do escravo ao trabalho livre, período em que grande parte da população de ex-escravos e seus descendentes passaram a se constituir em excedente para as necessidades médias do capital agrário (Pochmann, 2008).

Essa aproximação chama a atenção para o fato de que o preconceito racial no Brasil acabou definindo "o lugar" do negro no mercado de trabalho, ou seja, o negro passa a ser visto preponderantemente na desocupação, na informalidade e nas ocupações com precárias relações de trabalho. Assim, fazendo-se evidentes no cenário brasileiro após a constituição do trabalho livre, a desocupação e o trabalho precário, com que o negro se depara, se constituem expressões das estratégias de produção e subordinação do trabalho ao capital daquela fase histórica do capitalismo. Enquanto possuidor da mercadoria força de trabalho, os negros, a partir da transformação da ordem social, começam a competir com a força de trabalho imigrante. Por sinal, situação decorrente da política desenvolvida pela elite e pelo Estado com a finalidade de integração econômica, mediante a qual se volta para o "branqueamento da população brasileira", resultando, como observa Pochmann (2008), na "marginalização do negro" no mercado de trabalho emergente.

Fernandes (2007) observa que somente a partir da década de 1930, com o desenvolvimento urbano e a expansão agrícola, o negro passa a se inserir no mercado de trabalho, embora essa inserção esteja associada às atividades mais degradantes e, obviamente, às ocupações rejeitadas pelo trabalhador branco. Nesse contexto, a transição capitalista no Brasil se constituiu em um processo de profundas transformações. Iniciada na década de 1930, a industrialização, que se caracteriza inicialmente por ela restringida (1933-55), passa a um novo padrão de acumulação (industrialização pesada) somente a partir de 1956 (Draibe, 1985). A despeito dessas transformações operadas, o lugar do negro será mantido predominantemente no "exército dos desocupados" e/ou nas ocupações irregulares e degradantes (Martins, 2012). Portanto, o "lugar" dos negros passa a ser aquele relegado pelos não discriminados racialmente. 
Daí porque as desigualdades sociais e raciais devem ser buscadas na lógica capitalista, nas relações de produção, na estrutura de classes e, consequentemente, na forma de organização do poder no interior da formação social brasileira. É inerente ao modo de produção capitalista a produção e reprodução das desigualdades. É intrínseco também a esse modo de produção produzir desigualdade no interior das desigualdades. Daí porque as relações capitalistas não diminuem a distância entre todos os trabalhadores, mesmo como "cidadãos" da mesma classe. As relações de produção reproduzem as desigualdades, tanto as que propiciam a alienação do produto do trabalho e do trabalhador, quanto aquelas que no interior dessas relações fomentam e constroem a discriminação racial (Ianni, 1988). Não por outro motivo, as mediações entre determinações do racismo e determinações da sociedade de classes são fundamentais para dar conta das sequelas que a articulação dessas determinações deixaram na classe trabalhadora negra no país.

Parece-me evidente, portanto, que as desigualdades do negro no mercado de trabalho brasileiro estão correlacionadas com as crescentes estratégias de produção e subordinação do trabalho ao capital, ou seja, com a busca cada vez mais intensa de valorização do capital e extração de mais-valia. Contudo, se entrelaçam os elementos raciais que, a partir da dinâmica das relações sociais do capitalismo brasileiro, vão evidenciando os mecanismos que constroem e reconstroem - embora de forma velada e sob a égide da democracia racial — os elementos constitutivos da discriminação e da desigualdade racial no Brasil.

\section{0 negro no mercado de trabalho brasileiro: desemprego, trabalho precário e informal}

No Brasil, a reestruturação produtiva tem início nos anos 1980, com a retração de custo, mediante a redução da força de trabalho, via organização da produção, redução do número de trabalhadores, intensificação da jornada de trabalho, círculos de controle de qualidade total (CCQs) e dos sistemas de produção just-in-time e Kanbam. No entanto, é na década de 1990 que esse processo se intensifica mediante a intensificação da lean production, dos sistemas just-in-time e Kanban, do processo de qualidade total, das formas de subcontratação e terceirização da força de trabalho, da transferência de plantas e unidades produtivas (Antunes, 2006, p. 18).

Além dessas transformações, evidencia-se um processo de descentralização produtiva, no qual indústrias, a exemplo da têxtil, deflagram um movimento de 
mudança geográfica, procurando níveis mais rebaixados de remuneração da força de trabalho e incentivos fiscais advindos do Estado (Idem).

As sequelas desse processo de acumulação capitalista se evidenciam no desemprego estrutural, a partir do qual observa-se um grande enxugamento da força de trabalho que, combinado às mutações sociotécnicas no processo produtivo e à organização do controle social do trabalho, tem acarretado a flexibilização e a desregulamentação dos direitos sociais, principalmente via terceirização.

Esses complexos processos se somam ao contexto de desregulamentação do comércio mundial, que, no país, desencadeou, sobretudo na indústria automobilística, uma reestruturação produtiva via inovação tecnológica, introdução de mudanças organizacionais, acompanhado de relativa desverticalização, forte subcontratação e novas fábricas de tamanho reduzido, estruturas com base em células produtivas, além da ampliação de redes de empresas fornecedoras.

No mesmo processo, no setor financeiro os trabalhadores foram atingidos pelas mudanças nos processos e rotinas de trabalho, impulsionadas pela tecnologia de base microeletrônica e pelas mutações organizacionais. As políticas gerenciais são viabilizadas por meio de programas de "qualidade total" e "remuneração variável". Assim, as práticas flexíveis de contratação da força de trabalho nos bancos — mediante a ampliação significativa da terceirização, da contratação de trabalhadores por tarefas ou em tempo parcial, da introdução dos call centers - imprimiram maior precarização dos empregos e redução dos salários, aumentando o processo de desregulamentação do trabalho e da redução dos direitos sociais para os empregados em geral e, de modo mais intenso, para os terceirizados (Antunes, 2006).

Nesse contexto de desemprego estrutural e crescentes formas precárias de contratação, muitos trabalhadores dos diversos setores foram compelidos a desenvolver uma polivalência, além de terem aumentado de forma extenuante a jornada de trabalho.

A terceirização, por sua vez, ao atingir fortemente alguns setores da produção, desencadeou uma ampliação do trabalho em domicílios, nas pequenas unidades produtivas. Esse processo, além de alterar o espaço familiar e as condições de vivência, vem provocando uma degradação dos direitos sociais dos trabalhadores, a exemplo do descanso semanal e remunerado, férias, $13^{\circ}$ salário, aposentadoria. Ademais, evidencia-se uma ampliação do trabalho infantil, o que para Mészáros (2006) constitui um retorno da mais-valia absoluta.

Nesse sentido, Mészáros (2006) observa que a precarização do trabalho, expressa no mito da flexibilidade, está geralmente ligada à autoritária legislação antitrabalho, que estabelece lei tendencial da equalização descendente da taxa de 
exploração diferencial. Para o autor, trata-se da circunstância necessária à existência da globalização nas relações de produção e de distribuição. A equalização descendente das taxas de exploração diferenciais afeta cada um dos países capitalistas avançados, mesmo os mais ricos. O que torna a situação grave é que a precarização e a insegurança avançam pelos quatro cantos do mundo.

[...] o trabalho sem garantias mal pago está se alastrando como uma mancha de óleo, ao passo que mesmo o trabalho mais estável está sofrendo uma pressão em direção à intensificação sem precedente à plena disponibilidade para uma submissão aos mais diversificados horários de trabalho. (Trentacinque ore della mostra vita, Il manifesto, 13/2/1998, p. 5, apud Mészáros, 2006, p. 37)

Em se tratando das novas formas de trabalho, Vasapollo (2006) observa que o trabalho atípico e a precarização se colocam como elementos estratégicos dominantes do capital no paradigma pós-fordista. Nesse sentido, a flexibilização, em vez de aumentar os índices de ocupação, impõe a aceitação de salários reais mais baixos e em piores condições. Nesse contexto de reforço às novas formas de ofertas de trabalho difunde-se o trabalho irregular, precário e sem garantias.

Apesar da mundialização do desemprego e das formas precárias de trabalho é preciso observar que, embora a flexibilidade, o desemprego e a precarização sejam frequentemente associados à fase da acumulação flexível do capital, no Brasil,

tal questão aparece com traços específicos que the dão complexidade ainda maior. [...] É importante lembrar que em nosso país a dualidade e a heterogeneidade do mercado de trabalho são problemas histórico-estruturais, que já estavam presentes antes mesmo da crise que atingiu a economia mundial como um todo.

Assim, os problemas da "modernidade", decorrentes do novo paradigma tecnológico, da abertura dos mercados e da globalização financeira, se superpõem aos problemas do atraso (alto grau de informalização e de precariedade das relações de trabalho, desigualdade social, deficiências do sistema de proteção social, baixissimo nivel de escolaridade da força de trabalho). [...]

Esses fatores, num quadro de profundo atraso nas relações entre capital e trabalho, ajudam a entender o fato do país nunca ter tido, no passado, políticas públicas de emprego. Na verdade, o próprio conceito de política social tem existência recente em nosso país, pois durante décadas acreditou-se que a melhoria das condições de vida da população e do perfil de distribuição de renda seria uma consequência direta e inevitável do crescimento econômico. [...]

Destaca-se o grau de complexidade dos problemas associados ao mercado de trabalho no Brasil e, sobretudo, a dependência do enfrentamento desta questão ao equaciona- 
mento de inúmeros problemas no plano macroeconômico. (Azeredo, 1998, p.125-126; grifos meus)

Nesse sentido, a crise capitalista e a reação burguesa só intensificaram um processo já presente no regime de trabalho brasileiro - evidentemente resguardando as devidas especificidades. Contudo, é preciso sinalizar que embora esse processo tenha desencadeado efeitos sobre a classe trabalhadora, as novas estratégias de produção e subordinação do trabalho ao capital não atingem igualmente trabalhadores brancos e negros. Ao contrário, a histórica condição de precarização e informalidade do trabalho são reforçadas como o processo de crise e reestruturação produtiva. Nesse sentido, as "novas" formas de enfrentamento da crise, pelo capital, só fortaleceram e aprofundaram o desemprego da população negra, bem como a sua inserção no trabalho precário e informal.

Em 1998, as taxas de desemprego dos negros em seis regiões metropolitanas do Brasil foram superiores às dos(as) brancos(as). Além disso, entre o total de desempregados(as), igualmente a proporção relativa dos afrodescendentes era maior que a sua taxa de participação na PEA, chegando-se à situação extrema em Salvador, onde os negros, $79,9 \%$ da PEA, correspondiam a $86,4 \%$ do total de desempregados.

Nota-se que quando os(as) racialmente discriminados não estão compondo as taxas de desocupação/desemprego, a sua ocupação e/ou emprego, nos distintos ramos de atividades, está relacionada a uma maior concentração nas funções de menor prestígio social e econômico. Por exemplo, em 1998, na região metropolitana de São Paulo, a inserção dos(as) ocupados(as) negros(as) nos diferentes setores e ramos de atividades econômicas foi relativamente maior "nos serviços domésticos, na construção civil, na indústria têxtil, nos serviços de limpeza, reformas e transportes, e menor [...] [na] indústria química, serviços especializados, creditícios, educação, saúde, administração e utilidade pública" (Paixão, 2003, p. 107).

Esse quadro, mesmo quando se avalia considerando aquela "expulsão de massas de trabalhadores dos segmentos industriais e não industriais urbanos mais estruturados" a que se referem Baltar, Dedecca e Henrique (1996, p. 106) no âmbito das mudanças estruturais do pós-1990, observar-se-á que em 1998, "entre os afrodescendentes, a proporção de negros em funções precárias, em cinco das seis regiões metropolitanas cobertas pela $\mathrm{PED}$, era superior à casa dos $40 \%$, sendo invariavelmente superior à proporção de brancos na mesma situação" (Paixão, 2003, p. 108). Portanto, isto confirma que a despeito de a flexibilidade estrutural do regime de trabalho ter se aprofundado e se expandido na conjuntura que demarca o 
pós-1990, esse fato não altera a determinação da raça nos processos que conformam as relações capitalistas no Brasil.

Exemplo nesse sentido pode ser tomado pela proporção de trabalhadores(as) racialmente discriminados(as) nas ocupações informais e precárias, consideradas na PED (Dieese/Inspir, 1999) — analisada por Paixão (2003) —, como postos de trabalhos vulneráveis. ${ }^{2}$ Assim, a referida pesquisa deu conta de que a proporção de ocupados em postos de trabalho mais vulneráveis, segundo cor/raça, em seis regiões metropolitanas do Brasil, em 1998, é assim representada: em São Paulo 42,2\% dos ocupados nesses postos de trabalho são afrodescendentes (negros e pardos) e 32,2\% são da cor/raça branca e amarela; em Salvador, enquanto $27,3 \%$ são da cor/raça branca e amarela, 46,2\% são afrodescendentes; no Recife $44,7 \%$ são afrodescendentes e 36,8\% são branca e amarela; no Distrito Federal essa proporção para os afros chega a $35,4 \%$ e $25,2 \%$ para a branca e amarela; em Belo Horizonte $40,3 \%$ são afrodescendentes e $31,1 \%$, branca e amarela; em Porto Alegre, enquanto 32,4\% são da cor branca e amarela, 43,3\% são afrodescendentes.

Outro exemplo está na histórica inserção das mulheres negras brasileiras no emprego doméstico. Em 1998, nas seis regiões metropolitanas do país, as negras continuaram a se concentrar nessa ocupação. Em São Paulo, enquanto 5,9\% da PEA branca está no emprego doméstico, 14,3\% nesse emprego é da negra. Em Salvador são $12,1 \%$ da PEA negra e 3,7\% da branca. No Recife, 11,5\% da PEA negra está inserida no emprego doméstico, enquanto apenas $6,6 \%$ pertencem à PEA branca. No Distrito Federal o percentual chega a $14,7 \%$ da negra e $7,3 \%$ da branca. Em Belo Horizonte, enquanto 13,6\% da PEA negra ocupa esse emprego, da branca é ocupado por 6,5\%. Em Porto Alegre, ao contrário da participação de 6,5\% da PEA branca, a negra participa com 16,4\% (Dieese/Inspir, 1999, apud Paixão, 2003). Esse quadro não se alterou. Em 2009, no Brasil, "pretos e pardos são, em maior proporção, empregados sem carteira [assinada] e representam a maioria dos empregados domésticos" (IBGE/ PNAD, 2010, p. 230).

Dessa situação de trabalho resulta uma condição de vida diferenciada, seja pelo rendimento do trabalho abaixo do rendimento dos(as) demais trabalhadores(as) brancos(as), seja pela não participação no produto do trabalho social. Em 2008, "entre os $10,0 \%$ mais pobres, $25,4 \%$ se declararam brancos, enquanto $73,7 \%$ eram pretos e pardos. Essa relação se converte entre o 1,0\% mais rico: $82,7 \%$ eram pessoas brancas e apenas 15,0\% eram de cor preta e parda" (IBGE/PNAD, 2009, p. 187).

2. A PED toma como postos de trabalho vulneráveis os assalariados que não possuem carteira assinada, os autônomos que trabalham para o público, os trabalhadores familiares não remunerados e os empregados domésticos. 
Paixão e Carvano (2008), ao analisarem o desemprego, no período de 1995 e 2006 , tomando como referência a cor ou a raça e o sexo, constataram que do total de desocupados no país, $60,4 \%$ são pretos e pardos, dos quais $22,2 \%$ são homens e $40,2 \%$ são mulheres. Na PEA branca, os desocupados chegam a $38,3 \%$, sendo $9,8 \%$ de homens e $28,5 \%$ de mulheres.

Considerando o fato de que a reação burguesa à crise, no Brasil, fora intensificada na década de 1990, observa-se que enquanto em $1995,{ }^{3}$ os pretos e pardos correspondiam a $48,6 \%$ do total dos desocupados, sendo $25,3 \%$ homens e $23,3 \%$ mulheres, em $2006,{ }^{4} 54,1 \%$ do total de desocupados eram pretos e pardos, dos quais $23,9 \%$ eram homens e $30,8 \%$, mulheres. Assim sendo, em onze anos houve um aumento da população preta e parda desocupada. O quadro de desemprego da população preta e parda se confirma quando observada também por regiões do país. Nesse sentido, verifica-se a maior taxa de desocupação no Sudeste (11,3\% para homens e $15,1 \%$ para mulheres). No Norte, observa-se a menor taxa de desocupação para os homens (7,3\%), e no Sul, para as mulheres (10,4\%). Apesar dessas diferenças, em 2006 as taxas de desempregados da PEA preta e parda foram superiores à branca.

Se essa fase de desenvolvimento histórico do capitalismo traz como condição fundamental o desemprego, as novas estratégias de produção e subordinação do trabalho ao capital desencadeiam ainda uma realidade de precarização e informalidade que atinge toda a "classe-que-vive-do-trabalho". Nesse contexto, embora os trabalhadores de modo geral sejam afetados, são os grupos que historicamente se encontravam em desvantagem social que se inserem, em maior proporção, nas ocupações/trabalhos precários e informais. Daí porque (entre 1995 a 2006) na condição assalariada com carteira assinada havia uma presença maior dos trabalhadores brancos $(36,8 \%)$ do que entre pretos e pardos $(28,5 \%)$; entre os homens brancos $(39,8 \%)$ do que os pretos e pardos (33\%); e entre as brancas (33\%) do que entre as pretas e pardas (22\%). Da mesma maneira, as formas precárias de contratação são evidenciadas a partir dos indicadores trazidos por Paixão e Carvano (2008), ou seja, "o emprego assalariado sem carteira assinada era frequente aos homens pretos e pardos $(25,2 \%)$ do que aos brancos $(17,2 \%)$. Entre as mulheres, o percentual de pretas e pardas era ligeiramente superior (p. 94).

Em se tratando dos trabalhos que garantiam "maior estabilidade" e maior proteção social, a exemplo do emprego público, observa-se que este "era pouco

3. Primeiro ano do período considerado pela pesquisa.

4. Último ano do período considerado na pesquisa. 
mais frequente às mulheres brancas $(9,9 \%)$ do que às pretas e pardas $(7,5 \%)$ e aos homens brancos $(5,9 \%)$ do que aos pretos e pardos (4,6\%)" (Idem, p. 94). Em contrapartida, nas ocupações com maior instabilidade e com menor proteção social, a exemplo do trabalho doméstico, das pretas e pardas, uma em cada cinco era doméstica $(21,8 \%)$. Já a probabilidade de encontrar uma mulher branca no trabalho doméstico era 8,9 pontos percentuais inferior ao de pretas e pardas (Idem).

Nesse sentido, quando observamos os indicadores, o peso relativo do emprego sem a carteira assinada na PEA ocupada assalariada, tanto no setor privado quanto no público, no período em estudo, era de $25 \%$ para a PEA branca, sendo que nesse grupo de cor era de $27,3 \%$ para a masculina e de $23,9 \%$ para a feminina. Inserida nesses mesmos setores, a PEA preta e parda assalariada detém o peso relativo de $37,6 \%$ dos empregados sem carteira assinada. Ao decompor esse grupo de cor ou raça por sexo, verifica-se que a PEA masculina corresponde a $40,1 \%$, enquanto a feminina é de 32,5\%. Diante desses dados, quando analisado tomando como referência a cor ou raça, evidencia-se que enquanto os pretos e pardos $(55,5 \%)$ ocupam, em maior proporção, os trabalhos informais, sem carteira assinada, a presença relativa de trabalhadores brancos nos empregos privados com carteira assinada corresponde a $57,1 \%$ e no serviço público, nessa mesma condição, equivale a 57,8\% (Paixão e Carvano, 2008).

A análise do trabalho doméstico, como outra modalidade informal de ocupação, dá conta de que entre os pretos e pardos chega-se ao percentual de 75,8\% sem carteira assinada. ${ }^{5}$ Dentro desse grupo de cor ou raça identifica-se que $76,1 \%$ das mulheres e $63,6 \%$ dos homens encontram-se na mesma situação, ou seja, não possuem carteira assinada e, portanto, não possuem os seus direitos trabalhistas garantidos. Entre os brancos, $68,9 \%$ estavam inseridos no trabalho doméstico. Desse percentual, $57,1 \%$ eram homens e $69,8 \%$ eram mulheres. Ao observar, dentro do trabalho doméstico, os(as) trabalhadores(as) que possuíam carteira assinada, 53,8\% eram pretos e pardos, sendo que do total de empregados sem carteira assinada, o peso dos homens pretos e pardos correspondia a $3,3 \%$, e o das mulheres desse grupo, a $58,2 \%$.

No que se refere ao trabalho autônomo, observa-se o fato de que $10,1 \%$ dos brancos possuíam nível superior ${ }^{6}$ e apenas $1,9 \%$ dos pretos e pardos possuía esse

5. Para Paixão e Carvano (2008), "independentemente das clássicas definições da OIT e considerando as características do mercado de trabalho brasileiro, não parece razoável ocultar situações diferenciadas como a existência ou não de carteira assinada, no caso do emprego doméstico" (p. 96).

6. Da mesma forma, Paixão e Carvano (2008) observam que "independentemente das clássicas definições da OIT e considerando as características do mercado de trabalho brasileiro, não parece razoável ocultar 
grau de escolaridade. Assim, dos trabalhadores por conta própria $80,7 \%$ dos brancos tinham ensino superior completo, enquanto entre os sem ensino superior completo, $52,3 \%$ eram pretos e pardos.

A análise dos indicadores que apontam para as ocupações informais permite concluir que em 2006 a informalidade atingiu relativamente mais a população preta e parda. Melhor dizendo, enquanto $53,3 \%$ da PEA branca estava inserida em ocupações informais, esse percentual chegou a $65 \%$ da PEA preta e parda. Fazendo o recorte de cor ou raça e de gênero, verifica-se que 51,1\% da PEA branca era masculina, enquanto $54,1 \%$ era feminina. Da PEA preta e parda inserida na informalidade, $61,5 \%$ eram homens e quase $75 \%$ eram mulheres.

Os dados acima permitem afirmar que, mesmo considerando o contexto das novas estratégias de produção e subordinação do trabalho ao capital, os trabalhadores brancos concentram-se nas ocupações/emprego com registro em carteira de trabalho, no serviço público e militar, nas atividades por conta própria com ensino superior concluído e na condição de empregadores. Em relação aos trabalhadores negros (pretos e pardos), estes ocupam postos do mercado de trabalho sem carteira assinada, com predominante inserção no emprego doméstico, no trabalho por conta própria sem ensino superior completo, na construção para benefício próprio, de produção para o próprio consumo e não remunerado. Aqui se evidencia a condição de inserção dos trabalhadores negros no mercado de trabalho: com vínculos informais e com relações de trabalho extremamente precárias.

\section{Considerações finais}

A tentativa de entender os impactos das novas estratégias de produção e subordinação do trabalho ao capital parece evidenciar que a reação burguesa à crise estrutural do capital vem afetando em dimensão maior a parcela da classe trabalhadora negra. Essa constatação indica que embora o caráter estrutural das transformações no mundo do trabalho ocorra independentemente de fronteira societária, ele não isenta a possibilidade de impressão das marcas particulares de cada contexto social. No caso do Brasil, o racismo, ao se associar às "novas" relações, tem

\footnotetext{
situações diferenciadas como [...] a posse ou não do diploma de nível superior, no caso das ocupações autônomas" (p. 96). Para os autores, "ainda que o diploma não garanta atuação profissional na respectiva formação, não deixa de ser um indicativo sobre as diferentes probabilidades de vínculo com o mercado de trabalho como autônomo profissionais liberais" (p. 98).
} 
influenciado efetivamente para a concentração da classe trabalhadora negra no desemprego e/ou nas ocupações/empregos informais, com precárias relações de trabalho.

Recebido em: 27/4/2012 - Aprovado em: 6/6/2012

\section{Referências bibliográficas}

ANDREWS, G. R. Negros e brancos em São Paulo (1888-1988). Bauru: Edusc, 1998.

ANTUNES, R. Adeus ao trabalho? Ensaios sobre a metamorfose e a centralidade do trabalho. São Paulo: Cortez, 1997.

. A era da informatização e a época da informalização: riqueza e miséria no Brasil. In: (Org.). Riqueza e miséria do trabalho no Brasil. São Paulo: Boitempo, 2006.

AZEREDO, B. Políticas públicas de emprego no Brasil: limites e possibilidades. In: OLIVEIRA, M. A. (Org.) Reforma do estado e politica do emprego no Brasil. Campinas: Ed. da Unicamp, 1998.

BALTAR, P. E. de A.; DEDECCA, C. S.; HENRIQUE, W. Mercado de trabalho e exclusão social no Brasil. In: OLIVEIRA, C. A. B de; MATTOSO, J. E. L. (Orgs.). Crise e trabalho no Brasil: modernidade ou volta ao passado? São Paulo: Scritta, 1996.

DRAIBE, S. Rumos e metamorfoses: estado e industrialização no Brasil 1930-1960. Rio de Janeiro: Paz e Terra, 1985.

FERNANDES, F. A integração do negro na sociedade de classes. 3. ed. São Paulo: Ática, 1978. v. 1.

. A revolução burguesa no Brasil: ensaio de interpretação sociológica. 5. ed. São Paulo: Globo, 2006.

. O negro no mundo dos brancos. 2. ed. São Paulo: Global, 2007.

HARVEY, D. Condição pós-moderna: uma pesquisa sobre as origens da mudança cultural. São Paulo: Loyola, 1996.

IANNI, O. Raças e classes no Brasil. Rio de Janeiro: Civilização Brasileira, 1966.

. Escravidão e racismo. 2. ed. São Paulo: Hucitec, 1988.

. A questão racial no Brasil In: LOVELL, Peggy (Org.). Desigualdades sociais no Brasil contemporâneo. Belo Horizonte: UFMG/Cedeplar, 1991.

IBGE. Pesquisa Nacional por Amostra de Domicílios. Síntese de Indicadores Sociais: uma análise das condições de vida da população brasileira. Rio de Janeiro, 2009. 
MANDEL, E. O capitalismo tardio. São Paulo: Nova Cultural, 1982. . A crise do capital. São Paulo: Ensaio/Unicamp, 1990.

MELLO, J. M. C de. O capitalismo tardio. 9. ed. São Paulo: Brasiliense, 1994.

MARTINS, T. C. S. Racismo no mercado de trabalho: limites à participação dos trabalhadores negros na constituição da "questão social" no Brasil. Tese (Doutorado) — UFPE, Recife, 2012. MÉSZÁROS, I. Desemprego e precarização: um grande desafio para a esquerda. In: ANTUNES, R. (Org.). Riqueza e miséria do trabalho no Brasil. São Paulo: Boitempo, 2006.

. Para além do capital: rumo a uma teoria da transição. 3. reimpr. São Paulo: Boitempo, 2009.

NETTO, J. P. Cinco notas a propósito da questão social. Temporalis, Brasília, ano 2, n. 3, 2001.

PAIXÃO, M. Desenvolvimento humano e relações raciais. Rio de Janeiro: DP\&A/LPP/Uerj, 2003. (Col. Políticas da Cor.)

PAIXÃO, M.; CARVANO, L. M. Relatório anual das desigualdades raciais no Brasil: 2007-2008. Rio de Janeiro: Garamond, 2008.

POCHMANN, M. Rumos da política do trabalho no Brasil. In: SILVA, M. O. S.; YAZBEK, M. C. Políticas públicas de trabalho e renda no Brasil contemporâneo. São Paulo: Cortez; São Luís, MA: Fapema, 2008.

. Desempregos do Brasil. In: ANTUNES, R. (Org.). Riqueza e miséria do trabalho no Brasil. São Paulo: Boitempo, 2006.

SODRÉ, N. W. Historia da burguesia brasileira. 3. ed. Rio de Janeiro: Civilização Brasileira, 1976.

TEIXEIRA, F. J. S. Modernidade e crise: reestruturação capitalista ou fim do capitalismo? In: (Org.) Neoliberalismo e reestruturação produtiva: as novas determinações do mundo do trabalho. São Paulo: Cortez; Fortaleza: Uece, 1996.

VASAPOLLO, L. O trabalho atípico e a precarização se coloca como elemento estratégico dominante do capital no paradigma pós-fordista. In: ANTUNES, R. (Org.). Riqueza e miséria do trabalho no Brasil. São Paulo: Boitempo, 2006. 